\title{
SOBERANÍA ESTATAL Y COOPERACIÓN INTERNACIONAL. REFLEJOS DEL DERECHO INTERNACIONAL FRENTE AL DESAFÍO DE LA COVID-19 1
}

\author{
STATE SOVEREIGNTY AND INTERNATIONAL COOPERATION. REFLECTIONS \\ OF INTERNATIONAL LAW AGAINST THE COVID-19 CHALLENGE
}

Por Alberto César Moreira

\begin{abstract}
RESUMEN: La presente contribución reflexiona sobre dos principios medulares del Derecho internacional: la soberanía estatal y la cooperación internacional, en tanto que pueden visualizarse como los reflejos que está teniendo este orden jurídico en su respuesta ineficaz frente a la pandemia generada por el COVID-19. En ese sentido, por un lado, describe la evolución que ha experimentado el principio de soberanía en el Derecho internacional contemporáneo y destaca que la práctica estatal demuestra una revitalización del mismo. Por otra parte, pone de manifiesto la importancia de la cooperación internacional, pero expone las dificultades que está teniendo su realización en dos escenarios multilaterales centrales: la Organización Mundial de la Salud y el Consejo de Seguridad de las Nacionales Unidas. Finalmente, plantea el debate legal y ético para asegurar el acceso global a la vacuna contra el COVID-19, que constituye una prueba para la comunidad internacional y una oportunidad para construir un modelo de cooperación más solidario y eficaz frente a crisis globales
\end{abstract}

PALABRAS CLAVES: Derecho Internacional - CIVID 19 - Soberanía - Cooperación Internacional

\begin{abstract}
ABSTRAC: This contribution reflects on two central principles of International law: State sovereignty and international cooperation, while they can be seen as the reflections that this legal order is having in its ineffective response to the pandemic generated by COVID-19. In this sense, on the one hand, describe the evolution that the sovereignty principle has undergone in contemporary international law and highlight the state practice that demonstrates its revitalization. On the other hand, points out that the importance of international cooperation, but it exposes the difficulties that its implementation has in two central multilateral scenarios: the World Health Organization and the United Nations Security Council. Finally, it raises the legal and ethical debate to guarantee global access to the COVID-19 vaccine, which constitutes a test for the international community and an opportunity to build a more supportive and effective model of cooperation in the face of a global crisis.
\end{abstract}

KEY WORDS: International Law - CIVID 19 - Sovereignty - International Cooperation

\footnotetext{
${ }^{1}$ Artículo recibido el 13 de mayo de 2020 y aprobado para su publicación el 12 de junio de 2020.

Parte del contenido del artículo fue presentado en marco del Conversatorio Internacional "COVID 19 en América Latina: Situación y desafíos del Derecho Internacional”, organizada por la Universidad San Ignacio de Loyola (Perú) el 11 de abril de 2020.

(*) Abogado, Doctor en Derecho por la Universidad Nacional de Mar del Plata. Docente de grado, posgrado e investigador de la Facultad de Derecho de la dicha Universidad. Director del Instituto de Derecho Internacional del Colegio de Abogados de Mar del Plata. Contacto: albertocmoreira@,hotmail.com
} 


\section{(c) $(1)(2)$}

Artículo publicado bajo Licencia Creative Commons Atribución-No Comercial-Sin Derivar. (C) Universidad Católica de Córdoba

DOI http://dx.doi.org/10.22529/cdp.2020(8)05 


\section{SOBERANÍA ESTATAL Y COOPERACIÓN INTERNACIONAL. REFLEJOS DEL DERECHO INTERNACIONAL FRENTE AL DESAFÍO DE LA COVID-19}

\section{Introducción}

Desde hace unos meses nuestra vida ha cambiado. El mundo permanece en estado de alarma y consternación. En todas las lenguas se habla del nuevo Coronavirus, el COVID-19. Ese virus que se manifestó por primera vez en diciembre de 2019 en la ciudad china de Wuhan y que rápidamente se extendió prácticamente a todos los países del mundo. Las estadísticas de infectados y decesos inundan las redes y los medios de comunicación.

Es cierto que la historia universal registra muchas y graves epidemias e incluso pandemias, no siendo necesario hablar en tiempo pretérito, ya que varias enfermedades siguen produciendo estragos en distintos lugares del planeta, o resulta muy difícil erradicarlas, algunas endémicas, como el Dengue, el mal de Chagas o el Ébola.

Sin embargo, el COVID-19 ha impactado de una manera particular. Quizás sea por la incerteza científica sobre su origen y mutaciones, por la ausencia de un tratamiento médico eficaz y de vacunas, por el alto grado y velocidad de contagio. Tal vez, porque este virus no ha distinguido regiones, grupos sociales, ni el grado de desarrollo de los países. Luego de detectarse en China, el epicentro de los contagios se instaló en países desarrollados (primero fue Italia, luego España y le siguió los Estados Unidos) ${ }^{2}$, es decir en los llamados países del primer mundo, evidenciando que todos somos vulnerables. Además, esta pandemia se expande rápidamente en un mundo globalizado e interconectado como nunca antes, que se vio forzado a detener momentáneamente la circulación masiva de personas y frenar su frenética carrera de producción y consumo de bienes, en un modelo de crecimiento económico irresponsable por el grave deterioro del ambiente y la sobreexplotación de recursos.

La Asamblea General de las Naciones Unidas en su resolución 74/270 adoptada el 3 de abril de 2020, "Solidaridad mundial para luchar contra la enfermedad por coronavirus de 2019 (COVID-19)", ha calificado a esta pandemia como una amenaza a la salud, a la seguridad y el bienestar humanos, una grave disrupción de las sociedades y las economías. Además, reconoció que exige una respuesta mundial basada en la unidad, la solidaridad y una cooperación multilateral renovada, reafirmando su adhesión al multilateralismo.

2 Al momento de cerrar estas líneas, la Organización Mundial de la Salud advierte que el epicentro se ha instalado en América del Sur. Brasil ya es el tercer país del mundo con más casos, mientras Perú y Chile presentan un número creciente de pacientes. Noticias ONU. América del Sur, el nuevo epicentro del coronavirus, publicado el 22 de mayo de 2020, https://news.un.org/es/story/2020/05/1474862 (fecha de consulta 29 de mayo de 2020). 


\section{SOBERANÍA ESTATAL Y COOPERACIÓN INTERNACIONAL. REFLEJOS DEL DERECHO INTERNACIONAL FRENTE AL DESAFÍO DE LA COVID-19}

El nuevo Coronavirus impacta en la salud, en la vida cotidiana de mujeres y hombres del mundo, separa familias, arranca afectos, paraliza la economía, la producción y el trabajo.

Somos contemporáneos de esta tragedia sanitaria humanitaria y económica global, cuyos impactos en todas las áreas, entre ellas jurídicas e institucionales, aun no pueden evaluarse. Sin embargo, podemos reflexionar cómo está respondiendo el sistema internacional a esta coyuntura de emergencia y cuáles son los reflejos que ha despertado en el Derecho internacional.

En un reciente artículo de opinión, el jurista y filósofo italiano Luigi Ferrajoli critica la respuesta de los Estados europeos ante la pandemia, en lo que califica la insensatez de la soberanía nacional. Sostiene que sólo organismos supranacionales permitirán afrontar problemas y traspasar fronteras y se manifiesta acerca de la necesidad de una "Constitución de la Tierra"3. Su propuesta, que el propio autor reconoce utópica, resulta un interesante disparador para repensar sobre aspectos que resultan centrales en las relaciones internacionales y el derecho internacional.

En ese sentido, habremos de reflexionar sobre dos principios medulares del Derecho internacional: la soberanía estatal y la cooperación internacional, en tanto que pueden visualizarse como los reflejos que está teniendo este orden jurídico en su respuesta ineficaz frente a la pandemia generada por el COVID-19.

Por un lado, describiremos la evolución que ha experimentado el principio de soberanía en el Derecho internacional contemporáneo, destacando que la práctica estatal demuestra una revitalización del mismo. Por otra parte, pondremos de manifiesto la importancia de la cooperación internacional, y las dificultades de su realización, tomando dos escenarios multilaterales centrales: la Organización Mundial de la Salud y el Consejo de Seguridad de las Nacionales Unidas. Finalmente, plantearemos el debate legal y ético para asegurar el acceso

\footnotetext{
${ }^{3}$ Si bien Ferrajoli critica la respuesta de los Estados miembros de la Unión Europea, su propuesta es a escala global. Así, sugiere un demanio planetario para la tutela de bienes comunes como el agua, el aire, los grandes glaciares y los grandes bosques; la prohibición de las armas convencionales y las armas nucleares; el monopolio de la fuerza militar en manos de la ONU y un fisco global capaz de financiar los derechos sociales a la educación, la salud y la alimentación básica. El PAIS, Luigi Ferrajoli, filósofo: "Los países de la UE van cada uno por su lado defendiendo una soberanía insensata", entrevista publicada el 27 de marzo de 2020, https://elpais.com/ideas/2020-03-27/luigiferrajoli-filosofo-los-paises-de-la-ue-van-cada-uno-por-su-lado-defendiendo-una-soberania-insensata.html (fecha de consulta 20 de mayo de 2020).
} 


\section{SOBERANÍA ESTATAL Y COOPERACIÓN INTERNACIONAL. REFLEJOS DEL DERECHO INTERNACIONAL FRENTE AL DESAFÍO DE LA COVID-19}

global a la vacuna contra el COVID-19, que constituye una prueba para la comunidad internacional y una oportunidad para construir un modelo de cooperación más solidario y eficaz frente a crisis globales.

\section{La soberanía estatal: ¿un mal endémico del Derecho internacional?}

El Derecho internacional es un sistema de normas, reglas y principios que regula las relaciones entre los sujetos de Derecho internacional, con pretensión de alcanzar a la humanidad en su conjunto y, en su extremo individual, al ser humano. Cada vez de manera más clara penetra en los ordenamientos jurídicos nacionales, es decir en el derecho doméstico de los Estados que son los sujetos primarios, originarios y plenos de este ordenamiento.

Este orden jurídico, cuya acta de nacimiento convenientemente la doctrina la sitúa en el siglo XVII, con la Paz de Wesfalia ${ }^{4}$, se cimentó en la igualdad soberana de los Estados. Y es que el nuevo orden interestatal europeo que nació con los acuerdos de Osnabrück y Münster, se basó en un conjunto de normas que protegían la soberanía estatal $1^{5}$, igualdad soberana, integridad territorial, inmunidad de Estado, no injerencia en los asuntos internos.

Carrilo Salcedo, citado por Pérez González, ha dicho que la soberanía:

"se nos muestra como un principio constitucional del Derecho Internacional, símbolo del hecho de que este último opera sobre la base de coordinación entre los Estados y no de subordinación entre los mismos, y su esencia consiste en el derecho a ejercer las funciones de Estado en un plano de independencia e igualdad respecto de otros Estados"

Es sabido que la soberanía estatal tiene dos manifestaciones: una interna o summa potestas, que refiere al ejercicio de las funciones públicas sobre los individuos localizados en su territorio; en la plenitud de jurisdicción está la quintaesencia de la soberanía y otra externa, que podría

\footnotetext{
4 CASSESE, Antonio. International Law, 2da. edición, Oxford University Press, New York, 2005, p.22; DAILLIER, Philippe y PELLET, Alan. Droit International Public, $7^{\circ}$ ed., L.G.D.J., París, 2002, p.52, DIEZ DE VELASCO, Manuel. Instituciones de Derecho Internacional Público, Tecnos, Madrid, 14ª ed., 2003; BARBOZA, Julio. Curso de Organismos Internacionales, Zavalía, Buenos Aires, 2017, pp.9-10, entre otros.

5 DAILLIER, Philippe y PELLET, Alan, op. cit., p.52.

6 PÉREZ GONZÁLES, Manuel. "La Subjetividad Internacional”, DIEZ DE VELASCO, Manuel. Instituciones de Derecho Internacional Público, Tecnos, Madrid, $14^{\mathrm{a}}$ ed., 2003, p.222.

${ }^{7}$ CASSESE, Antonio, op. cit., p.48.
} 


\section{SOBERANÍA ESTATAL Y COOPERACIÓN INTERNACIONAL. REFLEJOS DEL DERECHO INTERNACIONAL FRENTE AL DESAFÍO DE LA COVID-19}

identificarse con la independencia. La expresión exterior de la soberanía, siguiendo a Barberis ${ }^{8}$, implica que su ordenamiento jurídico no se encuentra sometido al ordenamiento jurídico de ningún otro sujeto y solo limitado por el Derecho internacional.

Muchas transformaciones sociales, políticas y económicas se produjeron en la sociedad internacional: dos guerras mundiales, el proceso de descolonización de la década del 60 del siglo pasado, el fenómeno de la globalización y de la integración regional, el avance inusitado de la ciencia y de la tecnología, la sobreexplotación de recursos naturales, por señalar algunos. Sin embargo, el principio de soberanía se ha sostenido hasta la actualidad, acompañando la evolución del Derecho internacional.

Es cierto que también el orden jurídico internacional, como reflejo de esos cambios, experimentó una gran transformación, fundamentalmente a partir del siglo pasado, con el reconocimiento de nuevos sujetos distintos de los Estados, del ensanchamiento de las áreas y materias reguladas, una mayor institucionalización y la creación de múltiples instancias jurisdiccionales internacionales. Se verificó así una impresionante expansión normativa, en la que puede percibirse una tensión del principio de soberanía, dando como resultado una superación de la visión interestatal clásica del Derecho internacional. Se añade una dimensión general, que acepta la existencia de intereses comunes y compartidos por la comunidad internacional. Desde lo normológico, estas transformaciones fundamentan la existencia de normas de ius cogens, de erga omnes y la emergencia de conceptos como el patrimonio común de la humanidad, entre otras manifestaciones.

Así es posible hablar de un derecho internacional contemporáneo, que reconoce la existencia de intereses comunes que exceden el interés del Estado y que justifican la necesidad de repensar la soberanía estatal. Los dominios que más han contribuido en este cambio son el Derecho Internacional de los Derechos Humanos y el Derecho Internacional del Medio Ambiente. Ambos reflejan valores superiores que exceden el interés particular de los Estados y constituye una preocupación general, erosionando de algún modo las competencias nacionales ${ }^{9}$.

\footnotetext{
${ }^{8}$ BARBERIS, Julio. Los Sujetos del Derecho Internacional Actual, Tecnos, Madrid, 1984, pp. 41-42.

9 Cançado Trindade señala: "The expansion of the international normative corpus of human rights and the environment have been motivated by the needs of protection, in face of news threats and situations of no\begin{tabular}{llll}
\hline CUADERNOS DE DERECHO PUBLICO & VOLUMEN 8 & 2020 & Página 76
\end{tabular}
} 


\section{SOBERANÍA ESTATAL Y COOPERACIÓN INTERNACIONAL. REFLEJOS DEL DERECHO INTERNACIONAL FRENTE AL DESAFÍO DE LA COVID-19}

No estamos sosteniendo con ello que el principio de soberanía estatal haya quedado superado, sino, en todo caso, que se han redefinido o permeabilizado sus contornos, para poder responder a los nuevos desafíos que enfrenta la sociedad actual.

Parece una obviedad que emergencias mundiales, como la pandemia ocasionada por el COVID-19, deben afrontarse a nivel global, ya que la eficacia de la respuesta dependerá de la articulación y coherencia de las medidas que se adopten.

Sin embargo, como sucede en materia de migraciones internacionales, en la lucha contra el cambio climático, en las distorsiones proteccionistas al comercio internacional, por citar algunos problemas globales, la práctica estatal demuestra la vigencia y tal vez revitalización del principio de soberanía. Incluso ha quedado claro que la creación de órganos supranacionales no evita este fenómeno, como da cuenta el conocido proceso del Brexit, con el consecuente recupero por el Reino Unido de competencias delegadas a la Unión Europea.

Ante la coyuntura de la emergencia sanitaria los Estados se encaramaron sobre su soberanía y, ejerciendo la summa potestas, los gobiernos nacionales ensayaron respuestas distintas y claramente desarticuladas, en general con el objetivo de aplanar la curva de contagio, evitar el colapso de sus sistemas de salud y ganar tiempo para poder robustecerlos. Algunos adoptaron vigorosas medidas de aislamiento voluntario u obligatorio (incluso poniendo en tensión ciertas garantías individuales) y otros tomaron medidas más tibias. Ciertos Jefes de gobierno minimizaron los efectos de la pandemia, escépticos al principio se rindieron luego ante la evidencia y aún están quienes persisten en desacreditar las recomendaciones de los hombres de ciencia, planteando una falsa dicotomía entre salud y economía. El tiempo y los resultados darán la razón a unos u otros.

Hacia el afuera, los Estados limitaron o impidieron el ingreso de extranjeros, cerraron fronteras, llegando incluso a generarse tensiones diplomáticas por el tratamiento dispensado a extranjeros y comenzaron una carrera frenética para la adquisición de insumos e instrumental sanitario.

observance or violations of human rights, and the deterioration of the environment, to require responses of reparation or regulation. To the contemporary global approach to human rights and environment corresponds a global or integral protection.” CANÇADO TRINDADE, Augusto. O Direito Internacional em um mundo em transformação, Renovar, Rio de Janeiro - San Pablo, 2002, p.982. 


\section{SOBERANÍA ESTATAL Y COOPERACIÓN INTERNACIONAL. REFLEJOS DEL DERECHO INTERNACIONAL FRENTE AL DESAFÍO DE LA COVID-19}

En el plano discursivo, comenzó la atribución cruzada de responsabilidades y la difusión de hipótesis conspirativas, exacerbándose nacionalismos y xenofobia.

Sin embargo, estas manifestaciones no deben entenderse como consecuencias necesarias del legítimo ejercicio de la soberanía estatal. Tampoco debe soslayarse que el Derecho internacional contemporáneo ha desarrollado un andamiaje normativo e institucional, si bien limitado y con relativa eficacia, para dar algunas respuestas.

En primer lugar, podemos pensar en la activación de los mecanismos contemplados en los sistemas de promoción y protección de los derechos humanos, tanto por la omisión de actuar por parte de los Estados como por el exceso de algunas medidas adoptadas. $\mathrm{Y}$ es que las restricciones que los gobiernos adopten para proteger la salud pública y que pudieran suspender el ejercicio de ciertos derechos humanos, como la libertad de movimiento o de reunión, deberán cumplir los parámetros exigidos por el Derecho Internacional de los Derechos Humanos.

En tal sentido, la Oficina de la Alta Comisionada de la ONU para los Derechos Humanos publicó una guía dirigida a los Estados sobre cómo aplicar las medidas de emergencia en el contexto de la COVID-19, destacando los requisitos que rigen en la adopción de estas medidas de excepción: legalidad, necesidad, proporcionalidad y no discriminación ${ }^{10}$.

Por otra parte, al menos hipotéticamente, es posible pensar en la invocación de la responsabilidad internacional penal individual, como ya se ha intentado contra un jefe de Estado por el desmanejo de la crisis producida por la pandemia ${ }^{11}$, ya que se cuenta con la Corte Penal Internacional.

En el plano de la responsabilidad internacional del Estado, también podría activarse la invocación de responsabilidad no solo por la violación de normas convencionales, sino por

10 OFFICE OF THE UNITED NATIONS HIGH COMMISSIONER FOR HUMAN RIGHTS. Emergemcy Measures and COVI-19: Guidance, Documento disponible en:

https://www.ohchr.org/Documents/Events/EmergencyMeasures_COVID19.pdf.

11 La ONG Asociación Brasileña de Juristas por la Democracia habría presentado ante la Corte Penal Internacional una solicitud de investigación contra el Presidente del Brasil, Jair Bolsonaro, por la presunta comisión de crímenes de lesa humanidad contra la población ante la pandemia del coronavirus. ASOCIACIÓN BRASILEÑA DE JURISTAS POR LA DEMOCRACIA, comunicado del sito oficial: http://www.abjd.org.br/2020/04/abjd-denuncia-bolsonaro-por-crime.html (consultado el 22 de mayo de 2002). Esta información aún no ha podido corroborarse en el sitio oficial del Tribunal Internacional Penal. 


\section{SOBERANÍA ESTATAL Y COOPERACIÓN INTERNACIONAL. REFLEJOS DEL DERECHO INTERNACIONAL FRENTE AL DESAFÍO DE LA COVID-19}

incumplimiento al deber de prevención, en tanto se acredite que el presunto lesionante no haya tomado todas las medidas a su alcance para prevenir un daño del tipo transfronterizo.

Sin aventurar la suerte que pudieran tener cualquiera de estas posibles acciones, lo que quiere destacarse en este contexto, es que el acervo de Derecho internacional construido ofrece corpus normativos y herramientas institucionales, que son compatibles con el principio de soberanía estatal y que, de algún modo, configuran un contrapeso a su ejercicio.

En cualquier caso, como ya se ha dicho, queda claro que ante un desafío global de la magnitud de una pandemia y frente a la coexistencia de soberanías estatales y de instituciones internacionales de carácter regional y universal, resulta insoslayable la realización de la cooperación internacional. Y es allí donde se visualiza la mayor de las dificultades.

\section{La Cooperación internacional - solidaridad}

La actual pandemia se suma a una larga lista de problemas globales que superan las fronteras, como el cambio climático, la pérdida de la diversidad biológica, la crisis migratoria, el hambre mundial, entre otras, que encuentran terreno fértil para expandirse y profundizarse en un mundo claramente inequitativo.

Naturalmente, el logro de intereses compartidos exige la articulación de las diversas soberanías estatales y de las instituciones internacionales, tornando imprescindible la cooperación internacional.

Cooperar supone un marco de entendimiento sobre objetivos y compromisos entre actores; y la disponibilidad de mecanismos y procedimientos para el acceso a los recursos, los que generalmente consisten en proyectos de financiamiento, procesos de apoyo técnico y articulación de redes de conocimiento, incidencia y fomento de valores y buenas prácticas ${ }^{12}$.

Si bien la cooperación abarca todos los dominios de las relaciones internacionales, en materia sanitaria y frente a una situación de pandemia, deviene imprescindible. Su abordaje, además de medidas coordinadas a escala regional y global, exige conocimientos científicos, tecnología,

12 SOMMER, Christian, "El principio de cooperación internacional”, Cuaderno de Derecho Internacional, Número VIII, Los Principios Generales del Derecho internacional público: realidades y perspectivas, Córdoba, Academia Nacional de Derecho y Ciencias Sociales de Córdoba, 2013, p.174. 


\section{SOBERANÍA ESTATAL Y COOPERACIÓN INTERNACIONAL. REFLEJOS DEL DERECHO INTERNACIONAL FRENTE AL DESAFÍO DE LA COVID-19}

insumos y recursos financieros, bienes que suelen estar solamente a disposición de algunos Estados.

Podemos sostener que la cooperación internacional deriva del principio de solidaridad entre los Estados y que obedece a imperativos éticos y jurídicos. Sin embargo, la realidad nos demuestra que no existe cooperación inocente; a través de ella, las partes intentarán también concretizar intereses individuales, no siempre explícitos. Es una realidad subyacente que, si bien no enerva el valor de la cooperación en sí misma, afecta negativamente a su realización.

Dados los límites de esta intervención, habremos de referirnos solo a algunos escenarios multilaterales relevantes, que exhiben las dificultades para realizar la cooperación internacional, debido a conflictos de intereses que se ponen en juego.

\subsection{Embates a una Agencia especializada imprescindible en el actual contexto de pandemia}

La Organización de las Naciones Unidas ha sido un gran articulador de la Cooperación en todas las áreas, no siendo la excepción la sanitaria.

La cooperación internacional en esta materia se inició en la segunda mitad del siglo XIX, época en que las potencias europeas descubrieron su vulnerabilidad ante las denominadas enfermedades pestilentes, dándose a partir de allí una serie de conferencias, la adopción de algunos instrumentos e incluso la creación de instituciones ${ }^{13}$.

Sin embargo, la Conferencia de San Francisco de 1945 será el escenario de un renovado interés internacional por la salud. En esa oportunidad Brasil presentó un memorando que vinculaba salud y paz y junto con China propuso un proyecto de resolución para la creación de una organización sanitaria internacional. Esta resolución, aprobada por consenso, dará origen a la Organización Mundial de la Salud (OMS) ${ }^{14}$.

13 Un racconto de los desarrollos dados en la materia puede verse en SEUBA HERNANDEZ, Xavier, "La Organización Mundial de la Salud", en NEGRO, Sandra, (coord.). Pasado y Presente de las Organizaciones Internacionales OACI, OMPI, OMS y OEA, La Ley, 2011, pp.105-114.

14 Ibídem, p.114. 


\section{SOBERANÍA ESTATAL Y COOPERACIÓN INTERNACIONAL. REFLEJOS DEL DERECHO INTERNACIONAL FRENTE AL DESAFÍO DE LA COVID-19}

Su Constitución se adoptó por la Conferencia Sanitaria Internacional, celebrada en Nueva York del 19 de junio al 22 de julio de 1946, firmada el 22 de julio de 1946 por los representantes de sesenta y un Estados y entró en vigor el 7 de abril de $1948^{15}$.

La OMS, como Organismo Especializado de las Naciones Unidas, pone en contacto a los países para la búsqueda de soluciones a problemas comunes, actuando como intermediaria para la transmisión de conocimientos; facilita los intercambios entre los países y refuerza sus capacidades.

Por su competencia, universalidad y presencia territorial, es indudable el rol fundamental que cumple la OMS en el contexto de la pandemia y el liderazgo que está cumpliendo diariamente en la lucha contra el COVID-19. Sin embargo esta Organización, como todas, se rige por el principio de especialidad ${ }^{16}$, tienen límites competenciales y presupuestarios y es vulnerable a las presiones de los Estados, que utilizan esa arena para dirimir cuestiones de distinta naturaleza. Así, en plena crisis, cuando los contagios superan los millones de personas y resulta más que nunca necesario unirse para detener la pandemia, el Presidente de los Estados Unidos comunica la decisión de suspender el aporte de fondos a la Organización, luego de congelarlos de manera definitiva e incluso reconsiderar la membrecía ${ }^{17}$. La razón alegada es que la OMS había promovido la desinformación del Estado chino sobre el virus, lo que probablemente haya provocado que el brote sea más amplio de lo que debió haber sido ${ }^{18}$.

\footnotetext{
15 Todos los Estados miembros de las Naciones Unidas pueden llegar a ser miembros de la OMS aceptando su Constitución. Otros Estados podrán ser admitidos cuando sus solicitudes sean aprobadas por mayoría simple de votos de la Asamblea Mundial de la Salud. Los Miembros de la OMS (194 Estados) han sido divididos en grupos, según un criterio de distribución geográfica.

16 Las organizaciones internacionales no gozan de competencias generales y se crean para ejercer funciones específicas, rigiéndose por el Principio de especialidad. BARBOZA, Julio, op. cit, p.27. Respecto del principio de especialidad, cabe recordar la negativa de la Corte Internacional de Justicia a emitir la opinión solicitada por la OMS respecto de la legalidad de uso por los Estados de armas nucleares en situaciones de conflictos armados. Por aplicación del artículo 96, párrafo 2) de la Carta, la Corte de La Haya, en decisión muy cuestionable, consideró que la pregunta formulada no caía dentro del alcance de las actividades de esa Organización. Legality of the Use by a State of Nuclear Weapons in Armed ConJEict, Advisory Opinion, I. C. J. Reports 1996, p.66.

${ }^{17}$ LA REPÚBLICA. OMS lamenta que Trump corte el financiamiento cuando contagios siguen subiendo, publicada el 15 de abril de 2020, https://www.larepublica.co/globoeconomia/oms-lamenta-que-trump-le-corte-el-financiamientocuando-contagios-siguen-subiendo-2992552 (fecha de consulta 20 de mayo de 2020).

18 En una carta remitida al Director de la OMS el presidente de los Estados Unidos expresó que si esa Organización no se comprometía a realizar mejoras sustanciales en los próximos 30 días, haría permanente el congelamiento de fondos de ese Estado e incluso reconsideraría la membrecía. TÉLAM La OMS dijo que estudiará la carta en la que Trump le pidió cambios, publicada el 20 de mayo de 2020, \begin{tabular}{llll}
\hline \hline CUADERNOS DE DERECHO PUBLICO & VOLUMEN 8 & 2020 & Página 81
\end{tabular}
} 


\section{SOBERANÍA ESTATAL Y COOPERACIÓN INTERNACIONAL. REFLEJOS DEL DERECHO INTERNACIONAL FRENTE AL DESAFÍO DE LA COVID-19}

De ningún modo se está sosteniendo que la labor del Organización no pueda ser revisada ${ }^{19}$ e incluso, de corresponder, invocarse su responsabilidad. De hecho, en la $73^{\circ}$ Asamblea Mundial de la Salud, primera celebrada de manera virtual, se adoptó una resolución en la que, además de un llamamiento a la intensificación de esfuerzos para controlar la pandemia y al acceso equitativo y distribución justa de todas las tecnologías, se insta a iniciar, en el momento oportuno más temprano, un proceso progresivo de evaluación imparcial, independiente y exhaustivo de la respuesta mundial, que incluya el desempeño de la $\mathrm{OMS}^{20}$.

Luce un despropósito esta decisión política en el momento de mayor crisis, que socaba la legitimación de la Institución y reduce su capacidad de acción al quitar apoyo financiero, cuando en realidad los motivos subyacentes parecen ser de otra índole. Es fácil advertir que en el trasfondo está la puja de poder entre dos de las mayores potencias del mundo, que comienza siendo económica, luego tecnológica, de liderazgo y que hoy tristemente se instala en la lucha contra la pandemia ${ }^{21}$. Ya veremos cómo esta misma contienda proyecta sus reflejos en la labor del Consejo de Seguridad de las Naciones Unidas.

A pesar de lo dicho, la adopción por consenso de la resolución mencionada precedentemente y los términos en ella utilizados, que fue copatrocinada por más de ciento treinta Estados, representa un apoyo a la Organización ${ }^{22}$.

Adicionalmente, merece destacarse que en las dos resoluciones de las Asamblea General de las Naciones Unidas relativas al COVID-1923, aprobadas por consenso tácito ${ }^{24}$, se reconoce el

https:/ /www.telam.com.ar/notas/202005/466335-la-oms-dijo-que-estudiara-la-carta-en-la-que-trump-le-pidiocambios.html (consultado el 22 de mayo de 2020).

${ }^{19}$ Los cuestionamientos a la OMS no son nuevos. Por ejemplo, en oportunidad de la pandemia declarada por la influenza A H1N1 en 2009 se ha sugerido un accionar exagerado que beneficiaría a empresas farmacéuticas. Véase: PEREZ MIRANDA, Rafael. "Patentes, Monopolios y Competencia. El caso de los Productos Farmacéuticos”, BECERRA RAMIREZ, Manuel (coord.), Propiedad Intelectual y Farmacéutica. Hacia una Politica de Estado, Instituto de Investigaciones Jurídicas, Serie Doctrina Jurídica N 669, México, 2013, p.5.

${ }^{20}$ Resolución WHA73.1, adoptada por la $73^{\circ}$ Asamblea Mundial de la Salud el día 19 de mayo de 2020, Inciso 10).

${ }^{21}$ Cabe recordar otro caso que demuestra como las organizaciones internacionales están sometidas a los intereses políticos. En lo que a investigación científica se refiere, tampoco podemos olvidar la decisión de esa administración nacional de retirar financiamiento primero y luego retirarse de la Organización de las Naciones Unidas para la Educación, la Ciencia y la Cultura (UNESCO), cuyo trasfondo político fue el conflicto palestino/israelí.

22 Ver comunicado de prensa del 19 de mayo de 2020 de la OMS, https://www.who.int/es/newsroom/detail/19-05-2020-historic-health-assembly-ends-with-global-commitment-to-covid-19-response.

23 A/RES/74/270 adoptada el 3 de abril de 2020, "Solidaridad mundial para luchar contra la enfermedad por coronavirus de 2019 (COVID-19)" y A/RES/74/274 aprobada por la Asamblea General el 20 de abril de 2020, 


\section{SOBERANÍA ESTATAL Y COOPERACIÓN INTERNACIONAL. REFLEJOS DEL DERECHO INTERNACIONAL FRENTE AL DESAFÍO DE LA COVID-19}

papel rector crucial que desempeña la Organización Mundial de la Salud, lo que puede interpretarse como un respaldo de la comunidad internacional a esta Agencia internacional, más allá de los embates particulares.

\subsection{E1 estruendoso silencio del Consejo de Seguridad}

Otro claro ejemplo de las dificultades que enfrentan las Organizaciones Internacionales en la lucha contra el COVID-19 es la inaceptable inacción del Consejo Seguridad, que aún no ha logrado adoptar una resolución que dé respuesta al pedido de alto al fuego formulado por el Secretario General de la Organización ${ }^{25}$.

La inacción del Consejo de Seguridad desde que comenzó la pandemia también se debe a las profundas diferencias entre dos de los miembros permanentes, Estados Unidos y China ${ }^{26}$, primero por la inclusión o no del origen del virus en el texto de la resolución y, una vez superada esta diferencia, por la mención explícita o implícita de la Organización Mundial de la Salud.

Luego de semanas de negociaciones, se sometió a consideración el proyecto de resolución presentado por Túnez y Francia, que enfatizaba la necesidad de coordinación entre todos los Estados y demandaba un inmediato cese al fuego en todos los Estado, con exclusión de las operaciones militares contra el estado Islámico y todas las entidades terroristas listadas por el Consejo de Seguridad. Este proyecto no nombraba a la OMS, pero hacía referencia a agencias sanitarias especializadas, por lo que encontró oposición de los Estados Unidos, por considerar que se trataba de una referencia obvia, ya que la OMS es la única agencia de este tipo.

\footnotetext{
"Cooperación internacional para garantizar el acceso mundial a los medicamentos, las vacunas y el equipo médico con los que hacer frente a la COVID-19."

${ }^{24}$ Estas fueron adoptadas a través del procedimiento de acuerdo tácito o silence procedure adoptado días antes como un procedimiento para la toma de decisiones en el contexto del COVID-19.

${ }^{25}$ Con fecha 23 de marzo de 2020 el Secretario General de la Organización de las Naciones Unidas pidió un alto al fuego mundial para poder contener el Coronavirus. Noticias ONU, El llamado al alto el fuego mundial para ayudar a contener el coronavirus empieza a tener repercusión, publicado el 3 de abril de 2020, https://news.un.org/es/story/2020/04/1472342 (fecha de consulta 20 de mayo de 2020).

${ }_{26}$ Cabe recordar que, de conformidad con el artículo 27 inciso 3) de la Carta de San Francisco, para que el Consejo de Seguridad apruebe una resolución sobre cuestiones sustantivas (no de procedimiento) se requiere el voto afirmativo de nueve miembros, que incluyan los votos afirmativos de los cinco miembros permanentes (China, Estados Unidos, Francia, Federación Rusa y Reino Unido).
} 


\section{SOBERANÍA ESTATAL Y COOPERACIÓN INTERNACIONAL. REFLEJOS DEL DERECHO INTERNACIONAL FRENTE AL DESAFÍO DE LA COVID-19}

Más recientemente, Alemania y Estonia habrían presentado un nuevo proyecto de resolución, que también demanda un cese general de hostilidades en una veintena de naciones en crisis o en guerra y una pausa humanitaria por noventa días consecutivos a fin de facilitar la lucha contra la COVID-19. Este proyecto recogería los párrafos consensuados del proyecto anterior, pero omitiría mencionar a la OMS. A la fecha del presente la propuesta no ha sido aprobada ${ }^{27}$.

\subsection{E1 acceso universal a la vacuna - Un examen para la comunidad internacional}

Actualmente se están llevando a cabo numerosos programas de investigación en laboratorios de todo el mundo, en una carrera frenética por desarrollar en tiempo record la vacuna para el COVID-19.

Mientras ello ocurre, en la comunidad internacional se ha instalado un debate de orden legal y ético: ¿cómo asegurar que la vacuna que se desarrolle contra el COVID-19 llegue en condiciones igualitarias a todos los rincones del mundo y, fundamentalmente, a los países de bajos ingresos?

En realidad, esta emergencia revitaliza un debate que data de varias décadas ${ }^{28}$ y que, no sin controversias, en parte se encuentra regulado en el Acuerdo sobre los Aspectos de los Derechos de Propiedad Intelectual relacionados con el Comercio (ADPIC) ${ }^{29}$ y en la Declaración de Doha relativa al Acuerdo sobre los ADPIC y la Salud Pública ${ }^{30}$.

\footnotetext{
${ }^{27}$ France-24, New resolution on immediate global ceasefire presented to UN Security Council, nota del 13 de mayo de 2020, https://www.france24.com/en/20200513-new-resolution-on-global-ceasefire-during-covid-19-pandemicpresented-to-un-security-council (fecha de consulta 13 de mayo de 2020).

${ }^{28}$ Según Kors, el comienzo del siglo XX marcó el inicio de una nueva visión referida a la relación entre propiedad intelectual y el derecho a la salud. Luego de una serie de conflictos entre países miembros de la OMC, la Conferencia Ministerial de la OMC celebrada en Doha entre el 9 y 14 de noviembre de 2001 sobre cuestiones relacionadas con el ADIPC y la Salud Pública, aprobó una declaración por consenso cuyo origen es una petición de los países del Grupo Africano apoyado por otros países en desarrollo. KORS, Jorge. "Propiedad Industrial y Medicamentos en el Siglo XXI. La Cooperación entre los Países en Desarrollo", BECERRA RAMIREZ, Manuel (coord.), Propiedad Intelectual y Farmacéutica. Hacia una Politica de Estado, Instituto de Investigaciones Jurídicas, Serie Doctrina Jurídica N 669, México, 2013, p.67.

${ }^{29}$ El ADPIC constituye el Anexo IC del Acuerdo de Marrakech por el cual se crea la Organización Mundial del Comercio (OMC), que fue suscripto el 15 de abril de 1994 y entró en vigor el 1 de enero de 1995.

30 Si bien el Acuerdo ADPIC elevó notablemente los estándares de protección de los derechos de propiedad intelectual, las negociaciones internacionales, en especial las correspondientes a la Ronda de Doha, han esclarecido los márgenes que tendrían los paises en desarrollo y menos avanzados para establecer ciertas limitaciones que eviten los abusos monopólicos y estimulen el desarrollo de sus industrias nacionales. PÉREZ MIRANDA, Rafael. "Patentes, Monopolios y Competencia. El caso de los Productos Farmacéuticos", BECERRA RAMIREZ, Manuel (coord.), Propiedad Intelectual y Farmacéutica. Hacia una Politica de Estado, Instituto de Investigaciones Jurídicas, Serie Doctrina Jurídica N 669, México, 2013, p.18.
} 


\section{SOBERANÍA ESTATAL Y COOPERACIÓN INTERNACIONAL. REFLEJOS DEL DERECHO INTERNACIONAL FRENTE AL DESAFÍO DE LA COVID-19}

Este debate se enmarca en un contexto de grandes intereses económicos, en donde se presenta el problema de la propiedad intelectual, del control de patentes ${ }^{31}$ e incluso el derecho de ciertos Estados a un acceso prioritario a la vacuna y a un aprovisionamiento de la misma, por haber realizado mayores aportes económicos para las investigaciones. Si bien la situación no es nueva $^{32}$, la amenaza global por la actual pandemia debería constituir una oportunidad.

La Asamblea General de las Naciones Unidas, el día 20 de abril de 2020, aprobó la Resolución 74/274 "Cooperación internacional para garantizar el acceso mundial a los medicamentos, las vacunas y el equipo médico con los que hacer frente a la COVID-19”. A través de este instrumento se pretende promover y garantizar el acceso mundial a los medicamentos, las vacunas y el equipo médico para hacer frente a la COVID-19. En tal sentido, se solicita al Secretario General que, en colaboración con la OMS y otros organismos competentes del sistema, determine y recomiende opciones, incluidos enfoques para ampliar rápidamente la fabricación y fortalecer las cadenas de suministro que promuevan y garanticen el acceso justo, transparente, equitativo, eficiente y oportuno a instrumentos preventivos, pruebas de laboratorio, reactivos y materiales de apoyo, suministros médicos esenciales, nuevos diagnósticos, medicamentos y futuras vacunas de la COVID-19, así como su distribución en las mismas condiciones, con miras a ponerlos a disposición de todos los que los necesiten, en particular en los países en desarrollo. Además, se alienta a los Estados a aumentar la financiación de la investigación y el desarrollo de vacunas y medicamentos, reforzar la coordinación y a adoptar medidas para evitar la especulación y la acumulación indebida que puedan obstaculizar el acceso a los medicamentos esenciales, las vacunas y equipos de protección personal.

En sentido similar se ha pronunciado la Asamblea Mundial de la Salud en la Resolución WHA73.1 antes referida. Cabe destacar que en su párrafo 4) llama a eliminar urgentemente los

31 "A partir de que cobrara el acuerdo ADPIC, el sector (químico-farmacéutico) ha recibido severas críticas relacionadas con el abuso de la posición dominante en el mercado derivado del monopolio legal otorgado... Es quizás el sector en el cual el poder monopólico se ejerce con mayor fuerza y claridad, afectando un interés social e individual: el derecho de toda sociedad de tener acceso a los servicios de salud en igualdad de oportunidades." Ibídem, p.17.

${ }^{32}$ Ferrajoni, en el artículo antes mencionado (ver nota 3) señala que no todos los Estados pueden acceder a los 460 fármacos esenciales que, desde la Conferencia de Alma Ata de 1978, la OMS definió que deberían estar al alcance de todos. 


\title{
SOBERANÍA ESTATAL Y COOPERACIÓN INTERNACIONAL. REFLEJOS DEL DERECHO INTERNACIONAL FRENTE AL DESAFÍO DE LA COVID-19
}

obstáculos que dificulten el acceso, haciendo mención a la Declaración de Doha. El texto es el siguiente:

\begin{abstract}
"que hace un llamamiento se otorgue prioridad a nivel mundial al acceso universal, oportuno y equitativo a todas las tecnologías y productos sanitarios esenciales de calidad, seguros, eficaces y asequibles, incluidos sus componentes y precursores, que sean necesarios para la respuesta a la pandemia de COVID-19, así como a su distribución justa, y para que se eliminen urgentemente los obstáculos injustificados que dificulten dicho acceso y distribución, en consonancia con las disposiciones de los tratados internacionales pertinentes, en particular las disposiciones del Acuerdo sobre los Aspectos de los Derechos de Propiedad Intelectual relacionados con el Comercio (Acuerdo sobre los ADPIC) y las flexibilidades reconocidas en la Declaración de Doha relativa al Acuerdo sobre los ADPIC y la Salud Pública;"
\end{abstract}

Las dos resoluciones señalan un camino que debe transitarse de manera urgente y solidaria. El acceso global a la vacuna contra el COVID-19 constituye un imperativo ético y sanitario y exige una respuesta global y quizás un nuevo modo de cooperación, que no puede quedar librado al mercado.

Se necesitará una estrategia de cooperación mundial para la producción y distribución de la vacuna y un mecanismo de administración justa y equitativa para todos los pueblos, en particular para los de menores recursos, que pondrá a prueba al multilateralismo.

Como señala Bergel: "El acceso a los medicamentos necesariamente debe ser analizado y discutido en el ámbito general de la políticas sanitarias ya que de otra forma caemos en la simplificación - inaceptable por cierto - de dejar al mercado como regulador y árbitro de la salud colectiva, olvidando el compromiso primigenio del Estado para con la sociedad"33.

El punto de partida para las discusiones es considerar a la salud como un derecho humano y el acceso a la medicación, en este caso a la futura vacuna, como una pre condición para su goce. $\mathrm{Al}$ enmarcarse en un problema de políticas públicas sanitarias, deberían removerse las barreras de acceso, en especial aquellas ocasionadas por el efecto de los derechos de propiedad intelectual. No es descabellado en este contexto, proponer que dichas tecnologías sanitarias

\footnotetext{
33 BERGEL, Salvador Darío. "El Acceso a los Medicamentos como Derecho Humano: Reconocimiento y Limitaciones”, BECERRA RAMIREZ, Manuel (coord.), Propiedad Intelectual y Farmacéutica. Hacia una Politica de Estado, Instituto de Investigaciones Jurídicas, Serie Doctrina Jurídica N 669, México, 2013, p.81.
}

\begin{tabular}{llll}
\hline \hline CUADERNOS DE DERECHO PUBLICO & VOLUMEN 8 & 2020 & Página 86
\end{tabular}




\section{SOBERANÍA ESTATAL Y COOPERACIÓN INTERNACIONAL. REFLEJOS DEL DERECHO INTERNACIONAL FRENTE AL DESAFÍO DE LA COVID-19}

sean consideradas como bienes públicos globales, en sintonía con la propuesta de un demario que formula Ferrajoni en la nota que comentáramos al comienzo.

Frente a situaciones extremas como la actual pandemia, en donde está en juego la vida de millones de personas, la cooperación internacional no puede quedar atrapada en una lógica de disputas geopolíticas de ciertos Estados, ni en la puja de intereses económicos corporativos e incluso aspiraciones individuales.

Desde esta perspectiva, el contexto de crisis ofrece una oportunidad para dar un salto cualitativo en la cooperación internacional en materia sanitaria. Iniciativas, como la liderada por la OMS y Costa Rica para la creación del Fondo de Acceso a la Tecnología (C-TAP) y el reservorio de desarrollo científico, resultan auspiciosas ${ }^{34}$.

\section{Reflexiones finales}

A pesar de la perplejidad que nos causa la actual pandemia, algunas certezas quedan instaladas:

a) todos somos vulnerables, aunque las consecuencias, como siempre, recaerán en mayor medida en algunos; b) la práctica de los Estados, sujetos legiferantes principales en la elaboración de las normas internacionales, demuestra que el principio de soberanía, más allá de la permeabilización de sus contornos, exhibe renovada vigencia; c) en el contexto de crisis sanitaria se resalta el rol fundamental que tienen la ciencia y la tecnología, así como la necesidad de acudir a ellas en los procesos de toma de decisiones y d) resulta imperioso realizar la cooperación internacional y apuntalar el multilateralismo.

Retomando el artículo del jurista Ferrajoni, su valioso pensamiento, no exento de utopías, nos interpela a explorar caminos para construir un mundo mejor. Sin embargo, atribuirle al principio de soberanía todos los males es desatender cómo opera el sistema internacional, cuál es el telón de fondo en donde se desarrolla la obra, en definitiva, cuáles son las fuentes

\footnotetext{
${ }^{34}$ La OMS y Costa Rica han liderado una iniciativa, a la que ya han adherido treinta países, con la creación de Fondo de Acceso a la Tecnología (C-TAP) y de una plataforma de intercambio tendientes a que las vacunas, pruebas, tratamientos y tecnologías contra el COVID-19 sean accesibles para todos. Noticias ONU. La OMS y Costa Rica lanzan iniciativa para que las vacunas contra el coronavirus estén disponibles para todos, publicado el 29 de mayo de 2020, https://news.un.org/es/story/2020/05/1475182 (fecha de consulta 27 de mayo de 2020).
} 


\section{SOBERANÍA ESTATAL Y COOPERACIÓN INTERNACIONAL. REFLEJOS DEL DERECHO INTERNACIONAL FRENTE AL DESAFÍO DE LA COVID-19}

materiales que le dan sustrato a este limitado orden jurídico. Es que la soberanía y el propio Derecho internacional podrán ser bien o mal utilizados.

La soberanía estatal bien ejercida está limitada por el propio ordenamiento jurídico internacional del cual el Estado forma parte. Esto exige, entre otras obligaciones, el respeto de los derechos humanos, la prevención de los daños transfronterizos y la protección de los bienes comunes.

El equilibrio de intereses que ello importa exige desarrollar un esquema de responsabilidad internacional adecuado a la morfología de los problemas actuales ${ }^{35}$ y apuntalar la multilateralidad, la institucionalización y la cooperación internacionales. Una cooperación con solidaridad, que sea consciente de los desafíos y peligros comunes que enfrenta la sociedad actual, que sea respetuosa de las diferencias, que atienda las asimetrías, que contemple a los más vulnerables y que asuma el compromiso con las generaciones futuras. Debe propiciarse la construcción de una consciencia pública internacional solidaria de todos y especialmente de los actores con mayor peso.

Sin esta consciencia política la creación de Organismos Internacionales e incluso de instancias supranacionales no serán herramientas suficientes para allanar los caminos que solucionen los problemas a escala planetaria.

En suma, quizás el problema no radique en el Derecho internacional sino en la sociedad que está llamado a regular.

Hoy los ojos se posan en el desarrollo de la vacuna contra esta enfermedad y en el modelo de cooperación que pueda construirse para un acceso global de todos los pueblos del mundo. Es una verdadera prueba de fuego en donde la Organización de las Naciones Unidas y la Organización Mundial de la Salud resultan los escenarios naturales para edificar esta arquitectura.

\footnotetext{
${ }^{35}$ MOREIRA, Alberto "Aportes para una teoría general sobre responsabilidad internacional del Estado por daño ambiental”, MOREIRA, Alberto y PRIETO SANJUÁN, Rafael, (Coords.). La Responsabilidad Internacional del Estado y el Medio Ambiente Un debate urgente, Pontificia Universidad Javeriana - Biblioteca Jurídica Diké, Medellín, 2016.
} 


\section{SOBERANÍA ESTATAL Y COOPERACIÓN INTERNACIONAL. REFLEJOS DEL DERECHO INTERNACIONAL FRENTE AL DESAFÍO DE LA COVID-19}

¿Podrá esta pandemia despertar la conciencia de la comunidad internacional? Aspiramos a que la sociedad salga fortalecida de este flagelo y que las soluciones que se adopten produzcan cambios positivos y sostenibles en la cooperación entre los pueblos del mundo.

¿Deberemos aceptar que el Derecho internacional es una herramienta de los Estados para perseguir sus intereses nacionales? o podremos abrazar la idea de que los fines y la razón de ser de este ordenamiento jurídico son contribuir a resolver los problemas de la comunidad internacional mediante la cooperación internacional, fortaleciendo el imperio del derecho en las relaciones internacionales.

\section{Fuentes de información}

ASOCIACIÓN BRASILEÑA DE JURISTAS POR LA DEMOCRACIA, comunicado del sito oficial: http://www.abjd.org.br/2020/04/abjd-denuncia-bolsonaro-por-crime.html (consultado el 22 de mayo de 2002).

BARBOZA, Julio. Derecho Internacional Público, 2da. edición, Zavalía, Buenos Aires, 2008.

BARBOZA, Julio. Curso de Organismos Internacionales, Zavalía, Buenos Aires, 2017.

BARBERIS, Julio. Los Sujetos del Derecho Internacional Actual, Tecnos, Madrid, 1984.

BERGEL, Salvador Darío. "El Acceso a los Medicamentos como Derecho Humano: Reconocimiento y Limitaciones”, BECERRA RAMIREZ, Manuel (coord.), Propiedad Intelectual y Farmacéutica. Hacia una Política de Estado, Instituto de Investigaciones Jurídicas, Serie Doctrina Jurídica N 669, México, 2013.

CNESPAÑOL, La OMS analiza la carta de Trump en la que amenaza con retirar el apoyo económico de EE.UU, publicada con fecha 19 de mayo de 2020, https://cnnespanol.cnn.com/video/organizacion-mundial-salud-cnn-recibo-analisispresidente-eeuu-donald-trump-ayuda-economica-pandemia-coronavirus-tedros-adhanomghebreyesus-requena-panorama-cnnee/ (fecha de consulta 24 de mayo de 2020).

CIJ. Legality of the Use by a State of Nuclear Weapons in Armed ConJEict, Advisory Opinion, I. C. J. Reports 1996, p.66.

CASSESE, Antonio. International Law, 2da. edición, Oxford University Press, New York, 2005.

CANCADO TRINDADE, Augusto. O Direito Internacional em um mundo em transformação, Río de Janeiro, 2002.

DAILLIER, Philippe y PELLET, Alan. Droit International Public, $7^{\circ}$ ed., L.G.D.J., París, 2002. 


\section{SOBERANÍA ESTATAL Y COOPERACIÓN INTERNACIONAL. REFLEJOS DEL DERECHO INTERNACIONAL FRENTE AL DESAFÍO DE LA COVID-19}

DIEZ DE VELASCO, Manuel. Instituciones de Derecho Internacional Público, Tecnos, Madrid, $14^{\mathrm{a}}$ ed., 2003.

El PAIS, Luigi Ferrajoli, filósofo: "Los países de la UE van cada uno por su lado defendiendo una soberanía insensata", entrevista publicada el 27 de marzo de 2020, https://elpais.com/ideas/2020-0327/luigi-ferrajoli-filosofo-los-paises-de-la-ue-van-cada-uno-por-su-lado-defendiendo-unasoberania-insensata.html (fecha de consulta 20 de mayo de 2020).

FRANCE-24, New resolution on immediate global ceasefire presented to UN Security Council, nota del 13 de mayo de 2020, https://www.france24.com/en/20200513-new-resolution-on-globalceasefire-during-covid-19-pandemic-presented-to-un-security-council (fecha de consulta 13 de mayo de 2020).

KORS, Jorge. "Propiedad Industrial y Medicamentos en el Siglo XXI. La Cooperación entre los Países en Desarrollo", BECERRA RAMIREZ, Manuel (coord.), Propiedad Intelectual y Farmacéutica. Hacia una Política de Estado, Instituto de Investigaciones Jurídicas, Serie Doctrina Jurídica N 669, México, 2013.

LA REPÚBLICA, OMS lamenta que Trump corte el financiamiento cuando contagios siguen subiendo, publicada el 15 de abril de 2020, https://www.larepublica.co/ globoeconomia/oms-lamentaque-trump-le-corte-el-financiamiento-cuando-contagios-siguen-subiendo-2992552 (fecha de consulta 20 de mayo de 2020).

MOREIRA, Alberto "Aportes para una teoría general sobre responsabilidad internacional del Estado por daño ambiental", MOREIRA, Alberto y PRIETO SANJUÁN, Rafael, (Coords.). La Responsabilidad Internacional del Estado y el Medio Ambiente Un debate urgente, Pontificia Universidad Javeriana - Biblioteca Jurídica Diké, Medellín, 2016.

OFICINA DE LA ALTA COMISIONADA DE DERECHOS HUMANOS DE LAS NACIONES UNIDAS. Emergemy Measures and COVI-19: Guidance, https://www.ohchr.org/Documents/Events/EmergencyMeasures_COVID19.pdf.

ONU. A/RES/74/270 adoptada por la Asamblea General el 3 de abril de 2020, "Solidaridad mundial para luchar contra la enfermedad por coronavirus de 2019 (COVID-19)"

ONU. A/RES/74/274 aprobada por la Asamblea General el 20 de abril de 2020, "Cooperación internacional para garantizar el acceso mundial a los medicamentos, las vacunas y el equipo médico con los que hacer frente a la COVID-19."

Noticias ONU, El llamado al alto el fuego mundial para ayudar a contener el coronavirus empieza a tener repercusión, publicado el 3 de abril de 2020, https://news.un.org/es/story/2020/04/1472342 (fecha de consulta 20 de mayo de 2020).

Noticias ONU. América del Sur, el nuevo epicentro del coronavirus, publicado el 22 de mayo de 2020, https://news.un.org/es/story/2020/05/1474862 (fecha de consulta 29 de mayo de 2020). 


\section{SOBERANÍA ESTATAL Y COOPERACIÓN INTERNACIONAL. REFLEJOS DEL DERECHO INTERNACIONAL FRENTE AL DESAFÍO DE LA COVID-19}

Noticias ONU. La OMS y Costa Rica lanzan iniciativa para que las vacunas contra el coronavirus estén disponibles para todos, publicado el 29 de mayo de 2020, https://news.un.org/es/story/2020/05/1475182 (fecha de consulta 27 de mayo de 2020).

OMS, Resolución WHA73.1, adoptada por la $73^{\circ}$ Asamblea Mundial de la Salud el día 19 de mayo de 2020.

OMS, comunicado de prensa del 19 de mayo de 2020, https://www.who.int/es/newsroom/detail/19-05-2020-historic-health-assembly-ends-with-global-commitment-to-covid-19response.

PÉREZ GONZÁLES, Manuel. "La Subjetividad Internacional”, DIEZ DE VELASCO, Manuel. Instituciones de Derecho Internacional Público, Tecnos, Madrid, 14ª ed., 2003.

PÉREZ MIRANDA, Rafael. "Patentes, Monopolios y Competencia. El caso de los Productos Farmacéuticos”, BECERRA RAMIREZ, Manuel (coord..), Propiedad Intelectual y Farmacéutica. Hacia una Política de Estado, Instituto de Investigaciones Jurídicas, Serie Doctrina Jurídica N 669, México, 2013.

SEUBA HERNANDEZ, Xavier, "La Organización Mundial de la Salud”, en NEGRO, Sandra, (coord.). Pasado y Presente de las Organizaciones Internacionales OACI, OMPI, OMS y OEA, La Ley, 2011.

SOMMER, Christian. "El principio de cooperación internacional", Cuaderno de Derecho Internacional, Número VIII, Los Principios Generales del Derecho internacional público: realidades y perspectivas, Córdoba, Academia Nacional de Derecho y Ciencias Sociales de Córdoba, 2013.

TÉLAM. La OMS dijo que estudiará la carta en la que Trump le pidió cambios, publicada el 20 de mayo de 2020, https://www.telam.com.ar/notas/202005/466335-la-oms-dijo-que-estudiarala-carta-en-la-que-trump-le-pidio-cambios.html (consultado el 22 de mayo de 2020). 